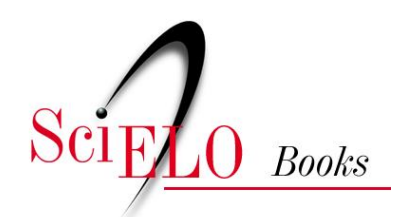

\title{
Misioneros y militares \\ Relaciones cercanas y distantes en la formación del Estado en el sur-oriente ecuatoriano, durante la primera mitad del siglo XX
}

\author{
Cecilia Ortiz Batallas
}

\section{SciELO Books / SciELO Livros / SciELO Libros}

ORTIZ BATALLAS, C. Misioneros y militares. Relaciones cercanas y distantes en la formación del Estado en el sur-oriente ecuatoriano, durante la primera mitad del siglo XX. In: JUNCOSA BLASCO, J., and GARZÓN VERA, B., eds. Misiones, pueblos indígenas y la conformación de la Región Amazónica: actores, tensiones y debates actuales [online]. Quito: Editorial Abya-Yala, 2019, pp. 89108. ISBN: 978-9978-10-494-1. https://doi.org/10.7476/9789978104941.0006.

\section{International license.}

Todo o conteúdo deste trabalho, exceto quando houver ressalva, é publicado sob a licença Creative Commons Atribição 4.0.

Todo el contenido de esta obra, excepto donde se indique lo contrario, está bajo licencia de la licencia Creative Commons Reconocimento 4.0. 


\section{Misioneros y militares. Relaciones cercanas y distantes en la formación del Estado en el sur-oriente ecuatoriano, durante la primera mitad del siglo $\mathrm{XX}^{1}$}

Cecilia Ortiz Batallas ${ }^{2}$

ceciortizb@gmail.com

\section{Puesta en escena}

Quienes circulaban por las calles de Quito la tarde del 24 de septiembre de 1944 presenciaron con asombro el arribo a la ciudad de más de un centenar de "jibaritos". La prensa hacía alarde del evento y mencionaba que los jóvenes iban descalzos, armados con lanzas, "atravesados palos en las orejas y en el rostro" y que, "pintarrajeados la cara, llevaban coloridas plumas en la cabeza" . Liderados por el pabellón nacional, con el pecho erguido y la mirada al frente, marchaban al ritmo de

1 Ponencia presentada en el X Congreso Ecuatoriano de Historia. Simposio Misiones, Pueblos Indígenas y la Conformación de la Región Amazónica. Cuenca, octubre de 2018.

2 Máster en Estudios Políticos y Doctora en Historia de los Andes por Flacso, Ecuador.

3 "El día de ayer tuvo lugar la inauguración de la Exposición Orientalista" (El Día, 25 de septiembre de 1944, p. 3). 
los aires marciales entonados por la banda del Batallón Vencedores. Los jíbaros - como se conoce al pueblo shuar, para la época, por lo que retomo esta denominación ${ }^{4}$ son los habitantes originarios del sur- oriente ecuatoriano, cuyos territorios se vieron atravesados por el conflicto limítrofe entre Ecuador y Perú, latente desde el nacimiento de la República en el siglo XIX (Cfr. Espinosa, 1999). ${ }^{5}$

Escoltaban a los visitantes los misioneros y misioneras salesianos, pertenecientes a congregaciones católicas creadas en Italia por Juan Bosco a mediados del siglo XIX (1859), a quienes el poder central del Ecuador delega la administración de la zona, en 1893 (Cfr. Guerriero \& Creamer 1997, pp. 45-46). Rodeaba el desfile una muestra de la flora y la fauna del entorno selvático. Los transeúntes se detenían para observar la exótica novedad, y brindaban calurosos aplausos a sus connacionales. Con este revuelo se festejaban los 50 años de permanencia de los salesianos en el Vicariato Apostólico de

Méndez y Gualaquiza, y se hacía pública la gestión de las misiones católicas en las selvas orientales. Se esperaba asimismo conseguir simpatías y contribuciones económicas del resto de ecuatorianos, a fin de sostener la obra misionera y civilizatoria ${ }^{6}$ en defensa de la frontera sur, así como de la nacionalización de su territorio y su gente. ${ }^{7}$

En otro escenario, un año antes, aparecen el Ministro de Defensa Nacional, Gral. Romero, autorizando a los salesianos

4 El tratamiento "jíbaros", del que fue objeto el pueblo shuar en la época de estudio, se mantiene en esta ponencia para mantener concordancia con el uso del lenguaje en el momento histórico. Desde 1964, este pueblo reivindica su autoadscripción identitaria y se reconoce como Shuar (FSCH, 1976, p. 121).

5 Esta ponencia retoma, en parte, elementos del artículo de mi autoría: "Las exposiciones orientalistas salesianas de 1943-1944: la puesta en escena del Estado en la Amazonía Ecuatoriana", publicado en 2017 en Procesos. Revista Ecuatoriana de Historia, 45, pp. 65-94. Recoge, asimismo, ideas de mi tesis doctoral (Ortiz, 2019).

La civilización es un proceso permanente que encuentra sus raíces en la cultura y organización social y política de los pueblos de "Occidente". La difusión de esta forma de vida como la dominante alude al proceso civilizatorio de los pueblos que detentan otras culturas (Cfr. Elias, 1989). tiembre de 1943, pp. 3,6). 
la utilización de las instalaciones del Colegio Militar para los

homenajes cincuentenarios, a desarrollarse con la Exposición Orientalista Nacional pro- Misiones Salesianas. ${ }^{8}$ El representante general de la congregación salesiana aceptaba la oferta y mencionaba que "los jíbaros" se preparaban para las competencias deportivas que se efectuarían con objeto de "hacer ver que la obra de civilización ha llegado al Oriente y pedir que los ecuatorianos finquemos nuestros anhelos en la imponderable riqueza de esta región". ${ }^{9}$ Entre tanto, se decoraba el escenario para las celebraciones: "En el jardín delantero del Colegio Militar se han instalado varios bombillos eléctricos y una alegoría luminosa de una cruz y una espada con los colores de la bandera nacional".${ }^{10} \mathrm{La}$ cruz y la espada mostraban, metafóricamente, la alianza entre los protagonistas de los acontecimientos.

\section{Los argumentos y metodología de investigación}

Las líneas que anteceden, y las ideas que expongo a continuación, dan la pauta para una interpretación sobre la formación del estado ${ }^{11}$ y la nación en el sur-oriente ecuatoriano. Argumento que la región, durante la primera mitad del siglo $\mathrm{XX}$, fue administrada por delegación, función que recayó en diversos actores, quienes ejecutaron algunas de las funciones que regularmente son realizadas por los gobiernos (Cfr. Ortiz, 2019). Se perciben como posibles autoridades, una burocracia local en muy lento proceso de consolidación, la asistencia pú-

8 AHMS Fondo: Relaciones Gobierno-Iglesia. Caja: Correspondencia Ministerios. Exp. X-8. "Comunicación del Crnl. Borja, [jefe de la I Zona Militar], a Mons. Domingo Comín, vicario apostólico de Méndez y Gualaquiza”, Quito, 23 de septiembre de 1943.

9 "Una espléndida exposición de lo que es nuestra región oriental" (El Día, 13 de septiembre de 1943, pp. 3, 6).

10 "La Exposición Orientalista. Ayer se inauguró el certamen en el edificio del Colegio Militar" (El Día, 3 de octubre de 1943, pp. 1 y 6).

11 No utilizo la mayúscula en "estado", pese a ir contra la norma de la Real Academia. De tal manera, interesa respaldar, desde el ámbito formal, un afán por desmitificar la idea del estado como un ente centralizado, monolítico y definitorio para las sociedades, idea en las que estas aparecen como pasivas. 
blica regional, los diputados en representación del poder Legislativo, o los organismos operadores en apoyo al progreso, entre otros. Aparecen, asimismo, agentes no oficiales como los empresarios, comerciantes, viajeros, colonos. Destacan entre ellos los misioneros católicos, y algunos protestantes, cuya llegada se incrementa en la época de interés, aunque su presencia ha sido histórica en la región ya desde el período hispánico.

Esta investigación particulariza el estudio de la acción de las misiones católicas y los militares, durante la primera mitad del siglo XX, dada la estrecha relación que sus funciones demandaron con el pueblo shuar, punto neurálgico de este escrutinio del proceso de construcción del estado. Propongo que los misioneros salesianos fueron el eje de esta delegación, papel que desempeñaron a través de pactos y convenios oficiales signados entre el gobierno del Ecuador y las autoridades de la Iglesia Católica -el Papa en El Vaticano-y con los mandos de la Casa de Don Bosco en Italia. ${ }^{12}$ Como se evidencia en este caso, la autoridad estatal no irradia desde un núcleo monolítico, ubicado en Quito como centro de poder, sino que se des-centra en distintos representantes para gobernar en los márgenes (Cfr. Krupa, 2010; Krupa \& Nugent, 2015; Ortiz, 2019). ${ }^{13}$

La presencia de los cuerpos armados en la zona respondió a una asignación de funciones, una vez que las fuerzas armadas, a diferencia de los misioneros, sí están incluidas en la estructura estatal (Cfr. Ortiz, 2006). Los militares atendieron a los requerimientos defensivos del territorio frente a los intereses de expansión del vecino Perú. ${ }^{14}$ Misioneros y militares

12 Solicitud y confirmación de la Santa Sede de la creación del Vicariato y asignación de su administración a los Hijos de Don Bosco (Guerriero \& Creamer, 1997, pp. 45-46). Hijos de Don Bosco como también se los denomina, por su filiación con el fundador de la Congregación Juan Bosco (Turín, 1859).

13 Los "márgenes", entendidos también como "periferias", no se interpretan en su dimensión espacial en esta ponencia, sino como las instancias donde se sitúan quienes no están del todo socializados en la ley: poblaciones que se integran a través de su conversión de "sujetos rebeldes" en sujetos leales al Estado (Daas \& Poole, 2008 [2004]), p.19).

14 En el contexto de surgimiento del Ecuador como República independiente (1830), su límites con los países vecinos no se marcaron definitivamente. A ello respondió la se- 
comparten la autoridad en este escenario, lo cual habla de una delegación múltiple de poder en el sur-oriente en el período de estudio. Esta situación genera momentos de acercamiento, así también otros de distanciamiento y conflicto entre los protagonistas de este segmento de la historia amazónica y de formación del estado en la región, como pretende probar la investigación que respalda estas reflexiones (Cfr. Ortiz, 2010; 2017; 2019).

Este estudio se divide en dos segmentos, uno que mira la relación de sinergia y colaboración que se establece entre salesianos y militares con objeto de civilizar/evangelizar al pueblo shuar, como estrategia de defensa de la frontera sur. Y un segundo momento en el que se observan episodios de distanciamiento entre estos actores, en situación de competencia por la administración del pueblo originario y su región. De tal manera, el conflicto, reflejado en situaciones de confrontación, aparece como uno de los componentes de la formación del estado y la nación y las relaciones cambiantes que se establecen entre quienes encarnan a la autoridad en la frontera sur del Ecuador, en la etapa que se analiza.

En la primera parte privilegio como fuente a la prensa quiteña, con los diarios El Comercio y El Día para obtener información sobre las "Exposiciones Orientalistas Salesianas", llevadas a cabo en Quito entre los años 1943 y 1944. Integro además documentación de primera mano obtenida en el Archivo Histórico de la Misión Salesiana (AHMS), y realizo una lectura interpretativa de la carga simbólica que portan estos eventos para proyectar, en la relación misioneros y militares, cómo se distribuyó el poder en la región durante la primera mitad del siglo XX.

La información recabada en el Archivo Histórico Salesiano (AHMS) en complementa con los datos en el Archivo de Centro de Estudios Históricos del Ejército (AHCEHE) para documentar la segunda parte de este estudio. Allí se dejan ver las tensiones que se provocaron entre soldados y sacerdotes en su afán 
por hegemonizar el control sobre los pueblos originarios y su territorio. Las memorias tanto de misioneros como de militares y pobladores shuar reafirman los resultados de la investigación de archivo, con lo que se consigue una visión más amplia y se ofrece un trabajo más sólido destinado al avance del conocimiento del surgimiento del estado en el sur-oriente ecuatoriano.

\section{El número cumbre de la raza jỉbara}

Así designaba la prensa de la época al acto representado por los niños y niñas shuar en el estadio del Instituto Nacional Mejía de Quito (septiembre de 1944). Allí se alineó la "guardia de honor", compuesta por un escuadrón de niños y niñas shuar vestidos como boy y girl scouts. ${ }^{15}$ Tras los acordes del Himno Nacional, el salesiano Elías Brito ${ }^{16}$ tomó la palabra para disertar sobre el significado de aquel acontecimiento: “...hacer una demostración de los frutos obtenidos durante cincuenta años de intensa labor de los misioneros salesianos en pro de la civilización del indio del Oriente y la formación de poblaciones progresistas en la selva”. ${ }^{17}$

Más de cien "jibaritos” descalzos marcharon vestidos con chaqueta y pantalón kaki y grandes pañuelos al cuello. Formaron hileras para agruparse en el centro, y marchando uniformemente, juraron lealtad a la bandera ecuatoriana ante el superior de la Misión Salesiana en Gualaquiza, el padre Simonetti (sdb). Según la nota de prensa, ellos prometieron con toda la fuerza de su acento robusto, defender y aún morir en resguardo de la bandera y de la patria ecuatorianas. ${ }^{18}$

15 "El día de ayer tuvo lugar la Exposición Orientalista" (El Día, 25 de septiembre de 1944, p. 3).

16 Brito (sdb) era el representante general de las Misiones Salesianas, en aquellos años, y sobresale por sus campañas nacionalistas y gestiones para ampliar la ocupación ecuatoriana en el oriente.

17 "El día de ayer tuvo lugar la Exposición Orientalista" (El Día, 25 de septiembre de 1944, p. 3).

18 "Una interesante revista de gimnasia presentaron los jibaros de nuestro Oriente" (EI Día, 6 de octubre de 1944, p. 8). 
El público aplaudía y los niños aclamaban: “¡Viva el

Ecuador!”, “'Gloria al Ejército ecuatoriano!”. El presidente Velasco Ibarra solicitó la "cooperación nacional" en bien de la región y felicitó a los salesianos y a la Iglesia Católica por su "don de adaptación a las circunstancias de la vida", su obra era "magnífica y favorecía a la especie humana." 19

Con aquel espectáculo, señalaba la prensa, el público constató la "inteligencia de la raza jíbara". Se destacaba que los salesianos habrían sido los mediadores para que, a través de la civilización, el "músculo obedeciera a la voluntad". Según el punto de vista que divulgó uno de los diarios quiteños, las guerras internas, una de las características de la cultura shuar, se habrían superado, "por manera que el Señor de la Selva, el dueño de la vida del vecino, ya no utilizará el método de fuerza, sino el de la convicción, primero meditará antes que lanzarse ciego, es decir, el tigre de la selva está ya dominado". ${ }^{20}$

Es reiterativo en el lenguaje periodístico, en el que se refleja en gran medida el habla coloquial, destacar la condición "salvaje" en proceso de conversión en positivo que ha conseguido la presencia misional en la región, en su intervención civilizatoria hacia los jíbaros (Cfr. Elias, 1989). Es palpable esta afirmación en el pasaje siguiente:

Donde antes reinaba la ignorancia y la abyección, hoy domina el triunfo de las Escuelas e Internados para niños y niñas jíbaros ... donde se levantaban las terribles y espeluznantes tsantsas, hoy se yerguen la cruz y la bandera nacional como símbolos de civilización y de progreso. (El Comercio, 20 de febrero de 1944)

Dobson y Zieman (2009, p. 7) llaman la atención en los usos de un lenguaje con juicios de valor, que se sostiene en oposiciones binarias entre grupos humanos diferentes. Uno de ellos 1944, p. 3).

20 "Una interesante revista de gimnasia presentaron los jíbaros de nuestro Oriente" (El Comercio, 6 de octubre de 1944, p. 8). 
aparece como inferior al otro, en una relación asimétrica que se respalda en un criterio que parte de un patrón ideal de cultura que es el que interesaba imponer. Desde otro enfoque, además, ello dejaba ver el "esfuerzo" que había comportado, para los religiosos, cumplir con su compromiso contraído con la religión católica y con los gobiernos ecuatorianos (Cfr. Ortiz, 2019).

Parte de la formación de los niños shuar con los misioneros se inspiró en el scoutismo o escultismo. ${ }^{21}$ Según sus seguidores, se trata de un movimiento que busca el desarrollo físico, moral e intelectual de los jóvenes. Aspira a capacitarlos para ejercer plenamente su libertad e integrarse a su comunidad con una actitud de servicio y trabajo. Se los entrena en la vivencia de estos principios, con base en una serie de actividades, muchas de las cuales se desenvuelven al aire libre; explorar en la naturaleza, es otro de los fundamentos de los scouts. Se guía por la idea del pluralismo religioso y social, sin distinción de raza, sexo o nacionalidad. Ha sido visto como un movimiento de voluntariado juvenil para formar buenos ciudadanos (Cfr. Moss, 2011). Surgió para combatir la delincuencia y fue pensado inicialmente como dispositivo para la formación de militares; posteriormente, se incluyó en el currículo de las escuelas inglesas de enseñanza media, para luego difundirse en el resto del mundo. Es un entrenamiento paramilitar y premilitar que prepara a los jóvenes para el ejercicio de la ciudadanía.

Este sistema fue adoptado en las escuelas que los salesianos regentaban en distintos puntos del país. ${ }^{22}$ En el medio ecuatoriano, durante el período de estudio, fue acogido como una estrategia para disciplinar a la juventud para el trabajo y militarizarla, dada la constante situación de emergencia bélica. Las autoridades de educación y las de defensa dispusieron glaterra (1907) https://bit.ly/2XKNCuv (Consultada en noviembre de 2018).

El fondo de imágenes del Archivo Histórico Salesiano contiene fotografías que dan testimonio de la práctica scout en las escuelas salesianas en el Colegio Santistevan de Guayaquil (1960, aprox.), en Ambato (1941). También en Riobamba, para 1941 se registra la práctica de los "exploradores" en el Colegio de los salesianos (Zambrano, 2014, p. 354; Cfr. Unda Lara \& Llanos Erazo, 2014). 
"establecer patrullas de boy scouts en las escuelas", entre los estudiantes de los grados superiores. ${ }^{23}$ Foucault recuerda que el modelo militar ha sido un medio fundamental para prevenir el desorden civil, que ha tenido influencia local y global.

La política como una técnica de la paz interna y el orden buscó implementar la idea de la armada perfecta, de la masa disciplinada, de una dócil y útil tropa del regimiento en campo y en maniobras y ejercicios. (Foucault 1984, p. 186)

Volviendo a los eventos de puesta en escena de la ecuatorianización de los niños, niñas y jóvenes jíbaros en Quito; en ellos, además, se enfatizó la función defensiva de los militares, habida cuenta que, aquel espacio habitado por el pueblo jibaro, era un territorio amenazado inminentemente por los intereses externos. Políticamente, eso era lo correcto. Vista desde esta perspectiva, la derrota del Ecuador en la guerra de 1941 frente al Perú, por el problema limítrofe, implicó que las fuerzas armadas justificaran su autoridad ante la sociedad, para viabilizar el resguardo limítrofe y conseguir el apoyo del resto de ecuatorianos. El presidente Velasco Ibarra explicaba —y a su vez legitimabaesta distribución de poder en aquella subregión: "He aquí por qué", decía el Presidente, "es saludable la obra de los misioneros salesianos y he aquí por qué es admirable la obra del Ministro de Defensa que estimula y protege a los Misioneros..."24

Al jurar fidelidad a la bandera nacional, los jibaritos daban señas de su voluntad de ser ecuatorianos - y no peruanos-. Lo que garantizaba la ocupación nacional de este territorio, con miras a evitar los avances del ejército del Perú. De esta

El "scoutismo" en el Ecuador se inicia en Guayaquil en 1913, para luego tomar fuerza en otras regiones del país. En 1968 el Ministerio de Educación declaró obligatoria la formación de Grupos Scouts en todas las escuelas y colegios del país, mediante el programa "Flor de lis, escultismo para jóvenes" (Distrito Scout Guayas. https://bit. ly/2YV2Rxm (Consultada en julio 16 de 2105).

24 Palabras del presidente Velasco Ibarra en el acto de presentación de la Revista de gimnasia, parte de los actos de la Exposición Orientalista de 1944, en el colegio Mejía. Quito, 24 de septiembre de 1944. "El día de ayer tuvo lugar la inauguración de la Exposición Orientalista" (El Día, 25 de septiembre de 1944, p. 3). 
manera, además, se integraban en la civilización pueblos considerados, hasta tanto, como "indómitos". El despliegue simbólico de la "jura de la bandera", por otro lado, es visto como un rito de paso que practican los jóvenes ecuatorianos, una vez que la educación que han recibido los ha concientizado sobre lo que implica suscribir la nacionalidad ecuatoriana. Segalen (2005, p. 32) define al ritual como "un conjunto de actos formalizados, expresivos, portadores de una dimensión simbólica”. El rito instituye "sanciona y santifica" un nuevo orden (Segalen, 2005, p. 54), tiene por efecto una sanción positiva del nuevo estatus de los individuos que han atravesado por este proceso. De tal manera, se los estimula a vivir según las expectativas sociales atribuidas al rango, pasa a ser uno más del grupo y deja de ser peligroso para el resto de miembros del grupo.

Los espectáculos salesianos de 1943 y 1944 caben interpretarse como recursos de "legibilidad del estado" (Scott, 1998) en la medida que dan cuenta de los actores y sus imaginarios sobre la autoridad estatal, y muestran cómo se administró estatalmente a la región. Desde otra lente, pueden observarse los episodios de fricción entre quienes protagonizan la historia que se analiza.

\section{Misioneros y militares, una relación cambiante y no siempre cercana}

Según lo divisado en los eventos expuestos, los tratos entre militares y religiosos dan cuenta de una condición armónica, que se simboliza en la imagen conjunta de la espada y la cruz, sin embargo, esta no fue la tónica constante de aquella relación. Hubo circunstancias de tensión entre estos actores, una de las cuales tuvo que ver con la primacía de uno u otro sobre el pueblo shuar, contexto en el que se detiene este segmento de la ponencia.

Uno de estos puntos de fricción se situó en el cumplimiento del Servicio Militar Obligatorio para los jíbaros. Este fue un deber para todos los varones mayores de dieciocho años residentes en el país, se estableció oficialmente a fines de la década de 
1930, si bien la ley que lo decreta fue dictada en 1904, durante

el régimen alfarista (Cfr. Coral, 1988). A más de conformar el "ejército del pueblo" para la defensa del territorio nacional (Cfr. Guerrero, 1924), este constituyó un mecanismo para incluir a los indígenas en el proceso disciplinario de formación del estado. Buscó, del mismo modo, conformar la nación homogénea culturalmente y unitaria, imaginada como objeto para conseguir una acción efectiva en la defensa de los límites territoriales, la "nación en armas" (Cfr. Ortiz, 2006). Fue, asimismo, un dispositivo de contacto del ejército con el pueblo, particularmente con el medio indígena y campesino. Pese a considerarse que aquella participación debía involucrar a todos los varones ecuatorianos, los reclutas en su mayoría, provinieron de los sectores populares (Cfr. García, 1987, p. 158; Ortiz, 2006). ${ }^{25}$

Por otro lado, los shuar fueron requeridos regularmente por quienes llegaban a la selva como cargueros, servicio que se les demandó del mismo modo, en el desempeño del Servicio Militar. Ello implica que a los jíbaros no se los tomó en cuenta como efectivos militares, hacia la década de 1940, sino como fuerza de carga, condición que los disgustó.

Así, la explotación por parte de los militares a la fuerza del trabajo shuar y el cumplimiento del Servicio Militar Obligatorio por parte de los jíbaros distanciaron a misioneros y militares en el suroriente, para la época. Recojo a continuación, ciertos episodios que reflejan lo afirmado hasta ahora. En julio de 1941, Juan Vigna (sdb) solicitaba al Jefe del IV Departamento militar, se dispense a los shuar de la conscripción. Aducía, para tal pedido, la "inconformidad" de los indígenas con esta obligación porque en el ejército se los hacía trabajar como "cargueros", tarea que los disgustaba, porque los soldados les conferían un trato violento (Bottasso, 1993, p. 130). 
No solo los conscriptos shuar fueron cargueros, se los requirió regularmente para este servicio, o como guías por la selva, también como "bogas" o "tamberos", es decir para conducir a quienes venían de fuera, por las vías fluviales de la región. La documentación militar registra Decretos Ejecutivos en los que se autorizaba la contratación a este personal civil por salarios mensuales de entre 150 y 210 sucres. ${ }^{26}$ Aparentemente, hubo oportunidades en que estos fondos no fueron entregados a los contratados, lo que elevó la queja de los salesianos a favor de los indígenas.

En esta misma línea, años más tarde en 1947, una solicitud de Mons. Comín (sdb), persuadía a los militares contra el maltrato a los indígenas, "so pena de que se fueran al Perú" (Bottasso, 1993, p. 131). Sin embargo, los cuerpos armados dependían de los "cargueros" shuar para su abastecimiento, y desde el Comando Militar se solicitaba a Mons. Comín mediar con ellos para que trasladaran los víveres a los destacamentos de avanzada. Estos son indicios, tanto el rechazo de los indígenas por cumplir con estas tareas, como de la dependencia que los militares debieron desarrollar frente a los misioneros para que interpusieran su influencia con los jíbaros, a fin del acarreo de los medios de subsistencia de los solados en la selva, entorno desconocido para estos últimos. Mostraba además que quien tenía injerencia sobre los indígenas eran los misioneros, situación reconocida por los militares, de ahí que le solicitaran a Mons. Comín interponer sus influencias con los indígenas para que los apoyaran (Ver remitido del Myr. Almeida en Bottasso, 1993, p. 131).

ACEHE Fondo: Órdenes Generales. Exp. V Zona Militar. De 2 de Nov. De 1945 a 25 de Dic. de 1945. Decretos Ejecutivos firmados por el presidente Velasco Ibarra entre febrero y diciembre de 1945, por pedido del Jefe del IV Departamento de Oriente consignando personal civil. Como "tamberos" son nombrados el "jíbaro Manuel Struve", para la sección de Macas, con sueldo mensual de ciento cincuenta sucres (19 de enero de 1945). Se registra un nombramiento de tambero-caminero para el "jíbaro" Pascual Rivadeneira quien prestaría sus servicios en el río Upano (26 de junio de 1945). Por igual medio. Otro registro menciona la destitución del cargo de tambero a Pedro Cayapa y se nombra en su reemplazo a Antonio Ajuanchi, ambos de ascendente "jíbaro" (30 de octubre de 1945), destinado al sector Chiguaza- Sangay. Los últimos percibirían salarios mensuales de 210 sucres. 
En la década posterior, en un comunicado dirigido al comandante general del ejército, fechado en 1950, el procurador de los salesianos Pedro Sagasti (sdb), le solicitaba eximir a los jíbaros del Servicio Militar Obligatorio. Justificaba su pedido en los acontecimientos "desagradables" ocurridos en el Limón. Se denunciaba que soldados liderados por el sargento Heredia habían irrumpido en la iglesia, "recinto sagrado", para reclutar a los jóvenes. Argumentaba que no ha existido el procedimiento de norma porque no se ha formulado la convocatoria para el alistamiento. Lo más grave, a juicio de Sagasti, radicaba en que "se ha encuartelado a los jíbaros"; y sostenía los mismos argumentos contrarios a tal situación, esgrimidos previamente por Mons. Comín (sdb): ellos, ante situaciones de amenaza, suelen desplazarse fuera de sus zonas de habitación regular huyendo a territorio peruano, "...con el inminente peligro de que se pierda todo lo conseguido con sacrificio: que amen el Ecuador y que sepan que el Perú es nuestro secular enemigo y nuestro voraz usurpador" ${ }^{27}$

Coinciden con las evidencias que dejan estos escritos, las memorias de misioneros que comparten lo vivido en el Vicariato de Méndez y Gualaquiza. Silverio Equizoaín (sdb) recuerda que aproximadamente por el año de 1956, los militares esperaban a indios y colonos a la salida de la misa y los reclutaban a la fuerza para cargar víveres a los destacamentos y guarniciones más alejados (Equizoaín (sdb), Macas, entrevistado por la autora en diciembre de 2015). Cuando ilustra la relación entre militares y salesianos, este personaje recuerda que pasó por momentos "fuertecitos" — caben interpretarse como problemas y roces, debidos a diferentes visiones con respecto al progreso o al tema de la ciudadanización de los pobladores shuar - .

Juan González (sdb), otro de los misioneros que vivió entre los shuar del Vicariato Apostólico de Méndez y Gualaquiza en la década de 1960, corrobora que fueron reclutados para la conscripción y amplía la información, diciendo que lo hicieron a la fuerza. 
Los llevaban a todos ... los cogían y los metían de cabeza y los llevaban a la conscripción... En Gualaquiza, había un cuartel desde donde salían en camioneta por las calles los domingos, y a todos los que cogían los llevaban al cuartel y les cortaban el pelo. (González (sdb), Macas, entrevistado por la autora en diciembre de 2015)

El Gral. Homero Berrazueta corrobora aquel reclutamiento forzado a los indígenas y campesinos, y aclara que ello ocurría hasta épocas previas a la década de 1960-1970, cuando los jóvenes indígenas se resistían a concurrir al Servicio Militar Obligatorio justamente por los reclutamientos forzados y sin previo aviso que provocaban aversión al cuartel. El cambio de actitud vino hacia la década de 1970 y según opinión de este militar, esto ocurrió seguramente por influencia del nuevo paradigma con respecto a los indígenas transmitido por la Iglesia Católica, con los cambios que se dieron a raíz del Concilio Vaticano II, los cuales infundieron una visión de mayor respeto para los pueblos indígenas (Berrazueta, Quito, entrevistado por la autora en noviembre de 2003).

El Crnl. Galo Cruz concuerda con lo enunciado por Berrazueta y, a su vez, señala que, en su opinión, el cambio de actitud en los años 1970 respondió al nuevo paradigma con respecto a los pueblos indígenas que surge en la Iglesia Católica para la época, y en general en la visión de mayor respeto para los indígenas que se difunde en el concierto internacional (Cruz, Sangolquí, entrevistado por la autora en mayo de 2016). Es decir que, al parecer de este militar, las formas de acción eclesiástica, de una u otra forma, influyeron en la política interna de los militares hacia los indígenas en cuanto al tratamiento que dieron a los temas de la diversidad. ${ }^{28}$

Si bien se la toma en cuenta, habría que rastrear más a profundidad esta respuesta, y verificar si grafica el proceso. No se pierda de vista que viene de la opinión individual de un militar, pese a que no carece de lógica, reconociendo la influencia de la Iglesia Católica en el plano universal y la vinculación religiosa de las fuerzas armadas con el catolicismo. 
Los militares, por su parte, mostraban su incomodidad

frente a la actitud de algunos sacerdotes que, según su punto de vista, no perdían oportunidad para desprestigiar el trabajo defensivo de las fuerzas armadas. "Según comunicaciones recibidas en el Ministerio de Defensa Nacional", decía un oficio procedente de la Comandancia de la III Zona Militar, dirigido al Sr. Obispo del Vicariato de Méndez y Gualaquiza (1943), y se que:

Peligrosos detractores de la Ley de Servicio Obligatorio se dedican, en ciertos lugares del país, a realizar una propaganda dañina y tendenciosa, como aquella de que los analfabetos no están obligados al Servicio en filas ... Ud., Señor Coronel, se servirá arbitrar ... para que, desde la cátedra como desde el púlpito, se prevenga a la gente de tamaño absurdo. ${ }^{29}$

\section{Algunas reflexiones finales}

Las que expongo a continuación no son conclusiones, son más bien reflexiones que surgen a partir de los elementos que se despliegan en líneas anteriores, y otros que abren interrogantes, no así ideas de cierre.

En cuanto a la percepción de la voz de los jíbaros en los eventos que se estudian, esta no es del todo audible. Esto significa que lo visto en las reflexiones expuestas, remite a la historia "desde arriba", es decir, a las prácticas, rutinas y rituales de mando protagonizadas por el estado y por las clases dominantes (Cfr. Lagos \& Calla, 2007, p. 16). La historia "desde abajo" parte de una visión etnográfica e histórica, que toma en cuenta el ejercicio, tanto cotidiano como político, de los sectores subalternos en su relación con el poder y sus ideas con respecto al estado (2007, p. 17), nociones que no se vuelven evidentes en las fuentes consultadas. 
Los homenajes cincuentenarios salesianos traslucen la participación de los pueblos originarios en los eventos referidos como una invención externa, en virtud de una preconcepción donde lo blanco y católico eran considerados como lo superior y todo lo indio como inferior y "salvaje" que, sin embargo, daba muestras de ser redimible (Cfr. Ortiz, 2019).

La asunción de los niños, niñas y jóvenes shuar como ciudadanos se plasma en su representación simbólica en los eventos de 1944. La aparición de los "jibaritos" con su atuendo scout, pero descalzos, los expone como ciudadanos parciales evidenciando así el mito del estado liberal moderno en torno a la equidad que concede la ciudadanía a los individuos.

Llama la atención, asimismo, que los niños y niñas jíbaros rindieran su juramento de fidelidad al Ecuador, frente a la bandera, con el padre Simonetti en el comando del ritual, pese a la presencia de autoridades de mayor jerarquía en los eventos. Esta era otra forma de legitimar la autoridad de los misioneros, que se sellaba con la presencia de los asistentes a los actos que se revisan.

En su discurso, luego de la jura de la bandera de los niños, niñas y jóvenes shuar en septiembre de 1944, el presidente Velasco Ibarra describe la distribución de poder en el suroriente, y menciona a los militares como protectores de la tarea misional y señala su función de estímulo a este trabajo. Ello coloca a los militares en una posición superior en la jerarquía. Sin embargo, el poder de los misioneros sobre los shuar, a su vez, fue ratificado en el Contrato de Colonización que firman las autoridades de la Casa de Don Bosco con el poder Ejecutivo, en el que se otorga a los salesianos la condición de tutores de los jíbaros, como sus representantes legales. ${ }^{30}$ Ello explica la posición de protección propiamente, que los religiosos ejercen en los distintos episodios que documentan esta investigación.

En las fricciones y distanciamientos entre misioneros y militares, los jíbaros aparecen como la "manzana de la discorno. Contrato Misional y de Colonización 1944. Ver especialmente Art. 5 del Contrato en mención. 
dia”, su agencia se muestra más patente cuando se menciona

que ellos se resistían a transportar a través de la selva los alimentos de los soldados, hecho que provoca que los militares recurrieran a los misioneros para que previnieran a los indígenas de colaborar con los soldados, como se ha visto, sucedió en 1947.

Desde esta óptica de análisis, las tensiones entre misioneros y militares se provocaron por la disputa por el control social en la región, lo cual muestra que esta delegación de la autoridad tuvo unos límites, los cuales fueron marcados por los propios agentes del estado y las funciones que cumplieron. Entre misioneros y militares se produce una relación de sinergia funcional, así también una de tensiones y vigilancia mutua, que muestran que la que se proyectó en este escenario fue una relación de dominación sin hegemonía (Cfr. Guha, 1997). Hablan asimismo de la composición fragmentaria del poder, en la región, en la medida que son varios actores detentando la autoridad estatal. De tal manera, el estado no puede ser visto como una sola estructura integrada y monolítica, al contrario, es una arena del conflicto y muestra diferencias y escisiones internas.

Misioneros y militares compartieron escenario en la defensa de la patria frente al enemigo externo, lo que implicó la estatización y nacionalización de este territorio y se gente. Lo singular del caso radica en que las atribuciones de poder del estado fueran compartidas por los militares con los misioneros, de quien se esperaría más bien una presencia referida al campo espiritual. Sin embargo, no fue así, no se aspiraba con ello solo una incidencia en el plano religioso, sino al fortalecimiento del estado, la educación, ecuatorianización y civilización de los indígenas con el afán principal de defender la frontera y la soberanía del territorio nacional.

\section{Fuentes y bibliografía Archivos}

- Archivo Histórico de la Misión Salesiana (AHMS).

- Archivo Histórico del Centro de Estudios Históricos del Ejército (AHCEHE). 


\section{Periódicos}

- El Comercio: 1943-1944

- El Día: 1943-1944

\section{Fuentes secundarias}

Bonilla, A. (1999). Fuerza, conflicto y negociación. Proceso político de la relación Ecuador-Perú. En A. Bonilla (ed.), Ecuador-Perú. Horizontes de la negociación y el conflicto (pp. 1330). Quito: FLACSO.

Bottasso, J. (1993). Los salesianos y la Amazonía, vol. 3. Quito: Abya-Yala.

Coral, H. (1988). Alberto Enríquez Gallo. Quito: Banco Central del Ecuador.

Das, V., D. Poole. (2008). El estado y sus márgenes. Etnografías comparadas. Cuadernos de Antropología Social, 27, 19-52.

Dobson, M., \& Zieman, B. (2009). Introduction. En Miriam Dobson y Benjamin Zieman (Ed.), Reading primary sources (pp. 1-18). New York: Routledge.

Elias, N. (1989). El proceso de la civilización: investigaciones sociogenéticas y psicogenéticas. México, D.F.: Fondo de Cultura Económica.

Espinosa, C. (1999). La negociación como terapia: memoria, identidad y honor nacional en el proceso de paz Ecuador-Perú. En Adrián Bonilla (Ed.), Ecuador-Perú horizonte de la negociación y el conflicto. Quito: FLACSO.

Foucault, M. (1984). The Foucault Reader. Editado por Paul Ravinow. New York: Pantheon Books.

García, B. (1987). Militares, economía y lucha política. Ecuador en los años 70. (Tesis para la obtención del título de maestría). México D. F. Colegio de México.

Guerrero, C. (1924). Función social del Oficial. El Ejército Nacional, 18.

Guerriero, A., \& Creamer, P. (1997). Un siglo de presencia salesiana en el Ecuador 1888-1898. Quito.

Guha, R. (1997). Dominance without Hegemony. History and Power in Colonial India. Cambridge: Harvard University Press.

Krupa, C. (2010). State by Proxy: Privatized Government in the Andes. Comparative Studies in Society and History, 52(2), 319350 . 
Krupa, C., \& Nugent, D. (2015). Off-centered States. Rethinking State Theoough an Andean lens. En Christopher Krupa y David Nugent (Ed.), State Theory and Andean Politics (pp. 1-34). Philadelphia: University of Pennsylvania Press.

Lagos, M. L., \& Calla, P. (2007). El Estado como mensaje de dominación. En María Lagos y Pamella Calla (Ed.), Antropología del Estado. Dominación y prácticas contestatarias en América Latina (pp. 11-38.). La Paz: NNUU.

Moss, R. (2011). Scouts Ecuador. Quito: Ediecuatorial.

Ortiz, C. (2006). Indios, militares e imaginarios de nación en el Ecuador del siglo XX. Quito: Flacso, Abya-Yala.

(2010). Religión, nación e institucionalización en el espacio shuar: una revisión retrospectiva de los mecanismos de inserción del suroriente al territorio ecuatoriano. En Felipe Burbano de Lara (Ed.), Transiciones y rupturas. El Ecuador en la segunda mitad del Siglo XX (pp. 515-562). Quito: FLACSO, Ministerio de Cultura.

(2017). Las 'Exposiciones Orientalistas Salesianas de 19431944: la puesta en escena de la construcción del Estado en la Amazonía ecuatoriana'. Procesos. Revista Ecuatoriana de Historia, 45, 65-92.

(2019). Shuar, misioneros y militares. La formación del estado en el sur-oriente ecuatoriano (1893-1964). (Tesis para la obtención del Doctorado en Historia de los Andes). Quito: Flacso.

Scott, J. (1998). Seeing Like a State. How certain schemes to improve that the Human Condition Have Failed. New Haven/ London: Yale University Press.

Segalen, M. (2005). Ritos y rituales contemporáneos. Madrid: Alianza. Unda Lara, R., \& D. Llanos Erazo (2014). Proyecto salesiano Chicos de la Calle. En L. Vásquez, J.F. Regalado et al. (coord.), La presencia salesiana en Ecuador. Perspectivas históricas y sociales (pp.143-198). Quito: Salesianos Don Bosco, Abya-Yala, Universidad Politécnica Salesiana.

Zambrano, J. (2014). Un siglo de aporte salesiano al fortalecimiento de la identidad guayaquileña. En L. Vásquez, J.F Regalado et al. (coord.), La presencia salesiana en Ecuador. Perspectivas históricas y sociales (pp. 411-434). Quito: Salesianos Don Bosco, Abya-Yala, Universidad Politécnica Salesiana. 
Berrazueta, Homero Gral. (sp) (+). Ha recibido formación militar en Panamá y otros países de América Latina, en distintos campos como la enseñanza y la administración militares. Ocupó distintos cargos en representación del Ecuador y las fuerzas armadas fuera del país. Se desempeñó con cargos militares en distintas plazas del Ecuador (Quito, Entrevista de noviembre de 2003).

Cruz, Galo (Crnl.). Militar en servicio pasivo. Ex director de Movilización de las Fuerzas Armadas. Director del Centro de Estudios Estratégicos de la Universidad de las Fuerzas Armadas -ESPE- . Interesado en los estudios históricos militares, ha realizado distintas investigaciones en torno a esta temática (Sangolquí, entrevista de mayo de 2016).

Equizoaín, Silverio (sdb). Nació en Navarra, España en 1921. Llega al Ecuador en 1955 por su voluntad de trabajar en las misiones en Ecuador. Trabajó en Guayaquil y Cuenca y desde 1956 partió al suroriente, en donde realizó trabajo pastoral con colonos y shuar. Desde 1958 se situó en Bomboiza, en la actualidad radica en Macas (Macas, entrevista de diciembre de 2015).

González, Juan (sdb) Misionero salesiano. Nacido en 1933, en España, González trabajó desde la edad de 31 años, en los internados amazónicos, desde la década de 1960. Luego de una estadía en Cuenca, pasó al Vicariato de Méndez y Gualaquiza para misionar en las casas de Méndez, Kutchanza, Macas, Sevilla Don Bosco, Sucúa, en los internados y las escuelas de los niños shuar (Macas, entrevista de diciembre de 2015).

Karakras, Ampam. Nació en Limón, tiene 68 años. Exrepresentante en Quito de la FCSH. Ampam Karakras Ipiak, de nacionalidad shuar, pasó por el internado salesiano. Obtuvo el título de contador público en el Colegio Río Santiago y realizó estudios de auditoría y contabilidad en la Facultad de Ciencias Administrativas de la Universidad Central del Ecuador. Fue representante en Quito de la Federación de Centros Shuar. Por el momento, es consultor independiente en temas de interculturalidad y asuntos indígenas (Quito, entrevista de octubre de 2015). 